\title{
Fitness of Isolates of Phytophthora capsici Resistant to Mefenoxam from Squash and Pepper Fields in North Carolina
}

\author{
Adalberto C. Café-Filho, Departamento de Fitopatologia, Universidade de Brasilia, 70910-900 Brasilia, DF, Brazil; \\ and Jean Beagle Ristaino, Department of Plant Pathology, North Carolina State University, Raleigh, NC 27695-7616
}

\begin{abstract}
Café-Filho, A. C., and Ristaino, J. B. 2008. Fitness of isolates of Phytophthora capsici resistant to mefenoxam from squash and pepper fields in North Carolina. Plant Dis. 92:1439-1443.

Despite the wide adoption of mefenoxam (Ridomil Gold EC) for vegetables in North Carolina, the incidence of Phytophthora blight on pepper (Capsicum annuum) and squash (Cucurbita pepo) is high. Seventy-five isolates of Phytophthora capsici were collected in five pepper and one squash field in order to assess mefenoxam sensitivity. The relative fitness of resistant and sensitive isolates was contrasted in vitro by their respective rates of colony growth and their ability to produce sporangia in unamended V8 juice agar medium. In in vivo experiments, the aggressiveness of isolates on pepper was evaluated. The frequency of resistant isolates in North Carolina populations was $63 \%$, considerably higher than resistance levels in areas where mefenoxam is not widely adopted. Resistant isolates grew on amended media at rates $>80$ to $90 \%$ and $>100 \%$ of the nonamended control at $100 \mu \mathrm{g} \mathrm{ml}^{-1}$ and $5 \mu \mathrm{g} \mathrm{ml}^{-1}$, respectively. Sensitive isolates did not growth at 5 or $100 \mu \mathrm{g} \mathrm{ml}^{-1}$. All isolates from three fields, including two pepper and a squash field, were resistant to mefenoxam. Populations from other fields were composed of either mixes of sensitive and resistant isolates or only sensitive isolates. Response to mefenoxam remained stable during the course of in vitro and in planta experiments. Occurrence of a mefenoxam-resistant population of P. capsici on squash is reported here for the first time in North Carolina. When measured by rate of colony growth, sporulation in vitro, or aggressiveness in planta, fitness of resistant isolates was not reduced. Mefenoxam-resistant isolates from squash were as aggressive on pepper as sensitive or resistant pepper isolates. These results suggest that mefenoxam-resistant populations of $P$. capsici are as virulent and fit as sensitive populations.
\end{abstract}

Additional keywords: fungicide resistance, metalaxyl, oomycetes, phenylamides, stramenopiles

Phytophthora blight, caused by Phytophthora capsici, is a limiting factor for the production of pepper (Capsicum annuum) and squash (Cucurbita pepo), frequently causing devastating disease losses (26). Most current commercial pepper varieties are either very susceptible or only partially resistant, and disease management is achieved mainly by a combination of cultural practices, crop rotation, and use of fungicides $(13,26)$. The systemic phenylamide fungicide mefenoxam, which is closely related to metalaxyl, is widely used to protect susceptible hosts against $P$. capsici in North Carolina and elsewhere. However, development of resistance to these phenylamides among members of the oomycetes, including the genus Phytophthora and especially $P$. infestans, has been known for over two decades (8$11,14,19,21,25,28-30)$.

Resistance to metalaxyl in populations of $P$. capsici was first demonstrated ex-

Corresponding author: Jean Beagle Ristaino

E-mail: Jean_Ristaino@ncsu.edu

Accepted for publication 13 June 2008.

doi:10.1094/PDIS-92-10-1439

(C) 2008 The American Phytopathological Society perimentally in the laboratory in the 1980s (1-4). Bruin and Edington (3) showed that resistance in isolates of $P$. capsici was induced by successive transfers to sublethal doses of metalaxyl. These isolates were generally cross-resistant to other related fungicides. The authors also found that the resistant isolates generally grew much more slowly than parent strains on unamended V8 juice agar, suggesting reduced fitness in the absence of selection pressure from the fungicide. In addition, most of the adapted isolates reverted to sensitivity after successive transfers on unamended media (3), indicating that resistant isolates obtained by adaptive selection in vitro were less fit than the wild types. On the other hand, Bower and Coffey (2) induced metalaxyl resistance by chemical mutagenesis and found that most resistant isolates remained tolerant to metalaxyl and related fungicides without any loss of pathogenicity after many transfers in the absence of selection pressure (i.e., in unamended cornmeal agar [CMA]). These authors suggested that there was a risk of development of phenylamide resistance in populations of $P$. capsici under field situations. Nevertheless, in contrast to "aerial" Phytophthora species, such as $P$. infestans, field resistance to phenylamides in $P$. capsici populations occurred much later, possibly related to the significant soilborne phase in the pathogen life cycle or less use of the fungicide by pepper growers (22).

Significant insensitivity of isolates of $P$. capsici in the field to mefenoxam was first detected in pepper isolates from North Carolina and New Jersey in $1997(21,22)$. More recently, there have been reports of resistance to phenylamides among $P$. capsici isolates from cucurbitaceous crops elsewhere $(16,17,24)$. However, mefenoxam is still one of the most popular fungicides for the control of oomycetes, and is still used in North Carolina for management of disease caused by $P$. capsici. The fungicide is still recommended for control of the disease (20). Destructive epidemics of Phytophthora blight on both pepper and squash crops have been reported in fields where the fungicide is used in North Carolina, suggesting that the chemical control was not efficient.

Assessment of fungicide insensitivity is often done in vitro. Studies on the fitness and ability of mefenoxam-resistant isolates of $P$. capsici to cause disease are examined less frequently. Aggressiveness has been used as an indicator of noncompetitive fitness of fungicide-resistant isolates. In some instances, fungicide-resistant mutants may have lower fitness than the wild types, a trait that may be useful in devising fungicide management strategies for extending the chemical effectiveness (32). However, this may not hold true for oomycete resistance to metalaxyl $(6,7)$. Moreover, within the genus Phytophthora, isolates of $P$. infestans (14) and P. nicotianae (31) resistant to metalaxyl were more aggressive than their sensitive counterparts. The relative fitness of isolates of $P$. capsici resistant to mefenoxam is unknown.

We assessed the mefenoxam sensitivity of 75 isolates of $P$. capsici from populations collected in North Carolina in vitro and also conducted further tests in vitro and in planta to contrast biological and parasitic components of the life cycle of resistant and the sensitive isolates. A preliminary report of this study has been published (5).

\section{MATERIALS AND METHODS}

Assessment of sensitivity to mefenoxam in vitro. Seventy-five isolates of $P$. capsici were collected in the 2001 season from one squash and five pepper fields in North Carolina. Host tissue was surface- 
disinfected with $0.05 \%$ sodium hypochlorite for $1 \mathrm{~min}$, and isolations were made on KM medium (15) amended with hymexazol $\left(50 \mu \mathrm{g} \mathrm{ml}^{-1}\right)$. Petri dishes were incubated for 5 to 7 days in the dark at $24^{\circ} \mathrm{C}$, and colonies with characteristics of $P$. capsici were transferred to clarified V8 juice agar (200 $\mathrm{ml}$ of clarified V8 juice, $800 \mathrm{ml}$ of deionized water, $17 \mathrm{~g}$ of agar). V8 juice was clarified by filtration through a Whatman no. 4 filter after the addition of $2 \mathrm{~g}$ of $\mathrm{CaCO}_{3}$, followed by centrifugation at $4,340 \times g$ for $10 \mathrm{~min}$. The pathogen was identified based on colony characteristics on CMA, sporangial morphology on V8 juice agar, and by polymerase chain reaction (PCR) using the PCAP primer (27) following DNA extraction following a fast procedure (18). Colonies were kept at room temperature on CMA slants, and served as sources of isolates retaining their original field status. Experiments to test the sensitivity to mefenoxam were done within a month after isolation.

Sensitivity to mefenoxam was estimated by measuring the radial colony growth of individual isolates (75 isolates) on replicated plates of clarified V8 juice agar with mefenoxam (Ridomil Gold EC $480 \mathrm{mg}$ a.i./ $/ \mathrm{ml}^{-1}$ ) at concentrations of 0,5 , and 100

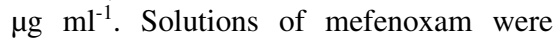
prepared in sterile water prior to amendment of the agar media. Agar disks $(5 \mathrm{~mm})$ were transferred to each of three plates of media at each level of fungicide. Plates were incubated in the light at $24^{\circ} \mathrm{C}$ for 4 days. Isolates were classified as sensitive, intermediate, or resistant based on their colony growth in the fungicide-amended media, relative to their respective growth on unamended clarified V8 juice agar (22). Isolates were characterized as sensitive if colony growth on media amended with 5 $\mu \mathrm{g} \mathrm{ml}^{-1}$ mefenoxam was less than $40 \%$ of that on unamended media. Intermediate isolates exhibited growth on media amended with $5 \mu \mathrm{g} \mathrm{ml}^{-1}$ greater than $40 \%$ of that on unamended media, but growth on media amended with $100 \mu \mathrm{g} \mathrm{ml}^{-1}$ less than $40 \%$ of that on unamended media. Resistant isolates exhibited growth on media amended with $100 \mu \mathrm{g} \mathrm{ml}^{-1}$ greater than $40 \%$ of that on unamended media (22). The experiment was repeated twice.

Rate of mycelium growth and capacity of sporangium production in una-

Table 1. Mefenoxam sensitivity among isolates of Phytophthora capsici collected from six North Carolina pepper and squash fields

\begin{tabular}{lccc}
\hline Crop/field & $\begin{array}{c}\text { Isolates } \\
\text { tested }\end{array}$ & Resistant & Sensitive \\
\hline Pepper field 1 & 13 & 13 & 0 \\
Pepper field 2 & 15 & 10 & 5 \\
Pepper field 3 & 12 & 0 & 12 \\
Pepper field 4 & 11 & 0 & 11 \\
Pepper field 5 & 9 & 9 & 0 \\
Squash field 1 & 15 & 15 & 0 \\
Totals & 75 & 47 & 28 \\
\hline
\end{tabular}

mended medium. Sporangium production was induced in nonclarified V8 juice agar. V8 juice agar cultures were incubated in the light at $24^{\circ} \mathrm{C}$ for $72 \mathrm{~h}$. Numbers of sporangia produced per plate were estimated after addition of $15 \mathrm{ml}$ of water per plate and subsequent sporangia extraction by gently rubbing agar surfaces with a glass loop, followed by collection of the sporangia suspension through cheesecloth and direct counts with a hemacytometer. Three experiments were performed with random combinations of isolates from different fields and hosts. Experiments A, $\mathrm{B}$, and $\mathrm{C}$ contrasted 3 resistant and 3 sensitive, 3 resistant and 2 sensitive, and 4 resistant and 4 sensitive isolates, respectively. Results were analyzed individually by isolate and also pooled by sensitivity categories in each experiment.

Aggressiveness in planta in the presence or absence of mefenoxam. Pepper seed (cv. Camelot) were planted in Styrofoam trays in potting mix and transplanted after 9 weeks to 6 -in. pots (1.7 liter volume) filled with vermiculite. Two to six days after transplanting, the soil was drenched with water or a solution of $5 \mu \mathrm{g}$ $\mathrm{ml}^{-1}$ mefenoxam prepared from commercial Ridomil Gold EC (48\% a.i. mefenoxam). Two days after the fungicide treatment, transplants were inoculated at the crown region with a 3-ml sporangium suspension consisting of either resistant or sensitive isolates at concentrations from $10^{3}$ to $10^{4}$ units $/ \mathrm{ml}$. Sporangia were produced and quantified as described previously and their numbers adjusted by dilutions with water so that all plants were inoculated with the same concentration of sporangia within each of four different experiments.

Isolates of $P$. capsici that were determined to be resistant or sensitive in in vitro experiments were tested for their aggressiveness in planta. Four sets of resistant isolates, including R5-2, R6-2, R19-2; R15-1, R16-2, R17-1, R18-2, R20-3; R1-2, R2-2, R16-2; and R1-2, R2-2, R6-2, R202 , and four sets of sensitive isolates, including S8-1, S10-1, S10-2; S7-2, S8-3, S9-2, S9-3; S9-2, S-Re9-2; and S11-1, S12-2, S9-2, S-Re9-2, were evaluated. Inoculum concentrations ranged from $4 \times$ $10^{2}$ to $4 \times 10^{3}$ sporangia/ml. Inoculated plants were between 7 and 12 weeks old. The experimental design was a factorial with two factors: isolates resistant or sensitive to mefenoxam and soil drenches of mefenoxam at two concentrations (water drench or $5 \mu \mathrm{g} \mathrm{ml}^{-1}$ mefenoxam drench). There were three replicate pots. One replicate (experimental unit) consisted of a pot with two to three plants per pot (subsamples). All pots were watered daily. Disease incidence was evaluated daily after inoculation, and disease progress through time was obtained for each treatment. Disease progressed from wilting plants to plants with stem lesions that expanded upward from the soil line. The rates of disease progress on plants in each treatment were used as estimates of respective aggressive levels of individual resistant or sensitive isolates in each experiment. Rates of disease progress were estimated and compared using an exponential model and the NLIN procedure of the SAS software (SAS Institute, Cary, NC) with disease as the dependent variable.

Stability of sensitivity and resistance to mefenoxam. Some plants inoculated with sensitive isolates in mefenoxamdrenched pots also became diseased 2 weeks after soil fungicide drench. Therefore, reisolations from these plants with symptoms that had been inoculated with sensitive isolates and treated with mefenoxam were performed on water agar or KM medium to determine the stability of sensitivity to mefenoxam. Growth rates of these reisolated cultures of $P$. capsici on V8 agar amended with 0,5 , and $100 \mu \mathrm{g} \mathrm{ml}^{-1}$ mefenoxam were measured in replicated tests and compared with the growth rate of their original corresponding parent field isolates. This procedure was repeated for the group of resistant isolates. Reisolations were done from all plants inoculated with isolates of $P$. capsici that were resistant to mefenoxam in vitro, and from plants in pots both treated and not treated with mefenoxam. For estimating the stability of resistance to the fungicide, the response to mefenoxam of the reisolated pathogen was compared with that of the original corresponding parent isolate.

\section{RESULTS}

Assessment of sensitivity to mefenoxam in vitro. The frequency of metalaxyl-resistant isolates of $P$. capsici was $63 \%$, and the frequency of sensitive isolates was $37 \%$. No isolates were classified as intermediate in sensitivity, sensu Parra and Ristaino (22). All isolates from two pepper fields and the squash field were resistant to mefenoxam (Table 1). Pepper field 2 had a mix of both sensitive and resistant isolates, and pepper fields 3 and 4 had only sensitive isolates (Table 1). Growth of resistant isolates on mefenoxam-amended media was usually $\geq 80$ to $90 \%$ and $\geq 100 \%$ of the nonamended control at the $100 \mu \mathrm{g} \mathrm{ml}^{-1}$ (Fig. 1) and $5 \mu \mathrm{g}$ $\mathrm{ml}^{-1}$ levels, respectively. Sensitive isolates did not grow at $5 \mu \mathrm{g} \mathrm{ml}^{-1}$, and no intermediate isolates were found (22). Reaction of each individual isolate to mefenoxam remained stable in the two repeated experiments.

Rate of mycelium growth and capacity of sporangium production in unamended medium. The overall rate of colony growth varied among individual isolates (not shown) and did not correlate with reaction to mefenoxam, host crop, or field of origin. Pooled average rate of growth of resistant isolates on clarified V8 juice agar was $93 \%$ of the pooled average 
rate of growth of sensitive isolates, and there were no significant differences between the two groups (Fig. 2). Numbers of sporangia recovered from plates were usually in the order of $10^{3} \mathrm{ml}^{-1}$ and varied among isolates (not shown). There were also no significant differences in numbers of sporangia produced between the resistant and the sensitive isolates (Fig. 3).

Aggressiveness in planta in the presence or absence of mefenoxam. A mefenoxam treatment of $5 \mu \mathrm{g} \mathrm{ml}^{-1}$ completely suppressed disease caused by sensitive isolates of $P$ capsici for approximately 10 to 12 days after soil drench with the fungicide (Fig. 4). Symptoms appeared later on mefenoxam-treated plants inoculated with sensitive isolates (Fig. 4). In contrast, disease progressed rapidly in plants inoculated with resistant isolates (treated or not treated with mefenoxam) or nontreated plants inoculated with sensitive isolates (Fig. 4). Disease protection against mefenoxam-sensitive isolates of $P$. capsici was less in experiment $\mathrm{D}$, in which plants were inoculated younger (7 weeks old), than in the other three experiments (Fig. 4D). First symptoms in mefenoxam-treated plants inoculated with sensitive isolates occurred 14 to 16 days after soil drench in experiments $\mathrm{A}$ to $\mathrm{C}$, but after 11 days in experiment D (Fig. 4). In all experiments, there were no clear differences in aggressiveness between the resistant isolates (whether treated or untreated with mefenoxam) and the sensitive isolates in the absence of mefenoxam (Fig. 4A to D). Disease progress curves were best described by a modified exponential model, $y$ $=2-2 \cdot \exp (r \cdot t)(P<0.0001)$, and the rates of disease progress between resistant isolates treated or untreated with mefenoxam and the sensitive isolates in the absence of mefenoxam were not significantly different $(P>0.05)$ when compared using a full model of the NLIN SAS procedure (Table
2). The full model considers all three treatments (Table 3 ) for the construction of one explanatory curve, while partial models consider two out of the three treatments.

The rates of disease progress of the mefenoxam-resistant and -sensitive isolates of $P$. capsici in pots drenched with water were contrasted as estimates of their respective aggressiveness in the absence of selection pressure. The $F$ test was used to compare differences between two treatments $\left[\left(\mathrm{SS}_{\mathrm{FM}}-\mathrm{SS}_{\mathrm{PM}}\right) *\left(\mathrm{PAR}_{\mathrm{FM}}-\mathrm{PAR}_{\mathrm{PM}}\right)-\right.$ $1] / \mathrm{MS}_{\mathrm{FM}}$, where $\mathrm{SS}=$ sum of squares of the residuals for the full model (FM) or the partial model $(\mathrm{PM})$, PAR $=$ parameters considered for each model, and MS = mean square. In all experiments, there were no differences in the rate of disease progress for the mefenoxam-resistant and -sensitive isolates of $P$. capsici in the absence of selection pressure by mefenoxam (Table 3). When isolates were compared by the host of origin, isolates from squash (all resistant) were as aggressive as the pepper isolates (sensitive or resistant) to the pepper host (data not shown).

Reaction to mefenoxam in vitro was stable in all reisolations after one pass through plants (data not shown). All sensitive isolates retrieved from plants grown in soil drenched with $5 \mu \mathrm{g} \mathrm{ml}^{-1}$ mefenoxam were as sensitive in vitro as the original isolates. The same was true for the resistant reisolates: resistant isolates retrieved from plants grown in soil drenched with water were as resistant in vitro as their counterparts retrieved from plants grown in soil drenched with $5 \mu \mathrm{g} \mathrm{ml}^{-1}$ mefenoxam or the original parent isolates kept in CMA slants.

\section{DISCUSSION}

Sixty-three percent of the isolates retrieved from pepper and squash fields in 2001 in North Carolina were resistant to mefenoxam. These levels are only slightly

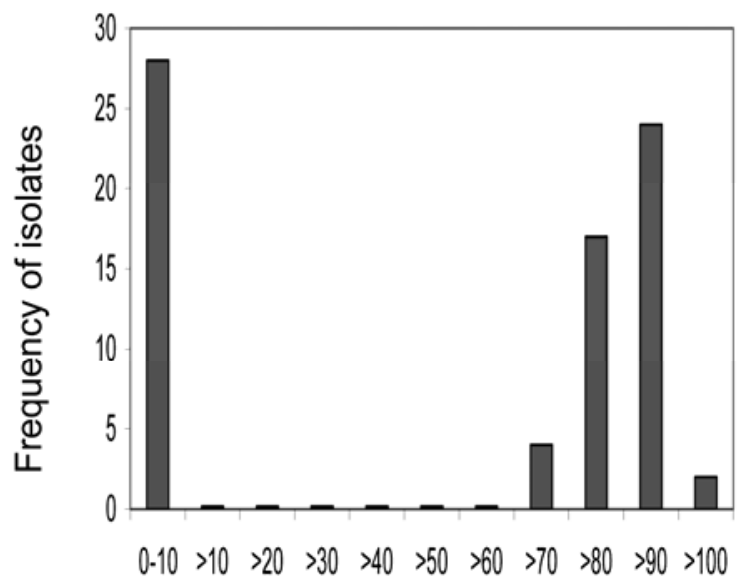

\section{$\%$ growth on $100 \mu \mathrm{g} \mathrm{ml}^{-1}$

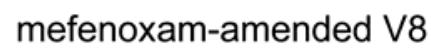

Fig. 1. Distribution of mefenoxam resistance among 75 isolates of Phytophthora capsici collected from commercial pepper and squash fields in North Carolina. higher than the levels detected in 1997 (59\% resistant isolates) and reported by Parra and Ristaino (22), suggesting that the frequency of resistance among $P$. capsici isolates has been stable over time in North Carolina. Also, mefenoxam had not been applied on the two fields where no resistance was found. Response to mefenoxam also remained stable during the course of experiments in vitro and in planta. Most resistant isolates usually grew at rates more than $80 \%$ (frequently more than $90 \%$ ) of the unamended control at the 100 $\mu \mathrm{g} \mathrm{ml}^{-1}$ level and more than $100 \%$ at the 5 $\mu \mathrm{g} \mathrm{ml}{ }^{-1}$ level (Fig. 1). Enhanced (i.e., $>100 \%$ ) growth rates of resistant isolates in fungicide-amended media are often found in in vitro studies with Phytophthora species, including $P$. capsici (22).

In unamended V8 juice medium, neither the rate of colony growth nor the rates of in vitro sporulation suggested any level of reduced fitness for the resistant isolates. Although these variables varied among individual isolates, the differences could not be explained as a function of the isolate response to mefenoxam. Radial rates of colony growth in unamended media were similar among isolates, with relative growth rates of resistant isolates $93 \%$ of

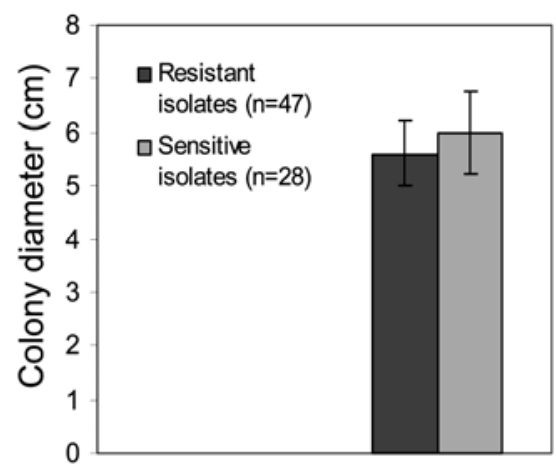

Fig. 2. Mean growth and standard deviation in unamended V8 juice agar of resistant (dark bar) and sensitive (light bar) isolates of Phytophthora capsici collected in North Carolina. Lines over bars represent standard deviations.

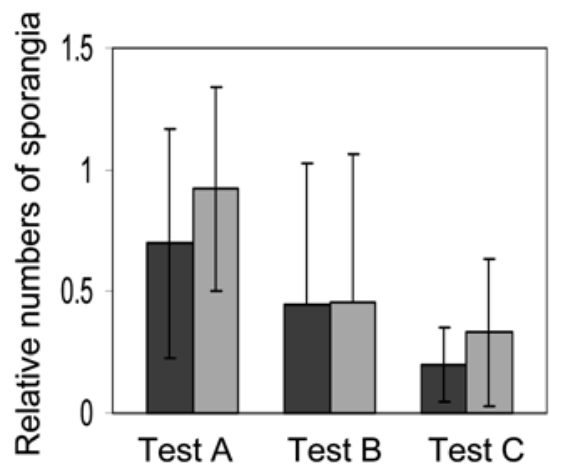

Fig. 3. Relative numbers of sporangia produced in vitro by resistant (dark bars) and sensitive (light bars) isolates of Phytophthora capsici in three separate tests. Lines over bars represent standard deviations. 

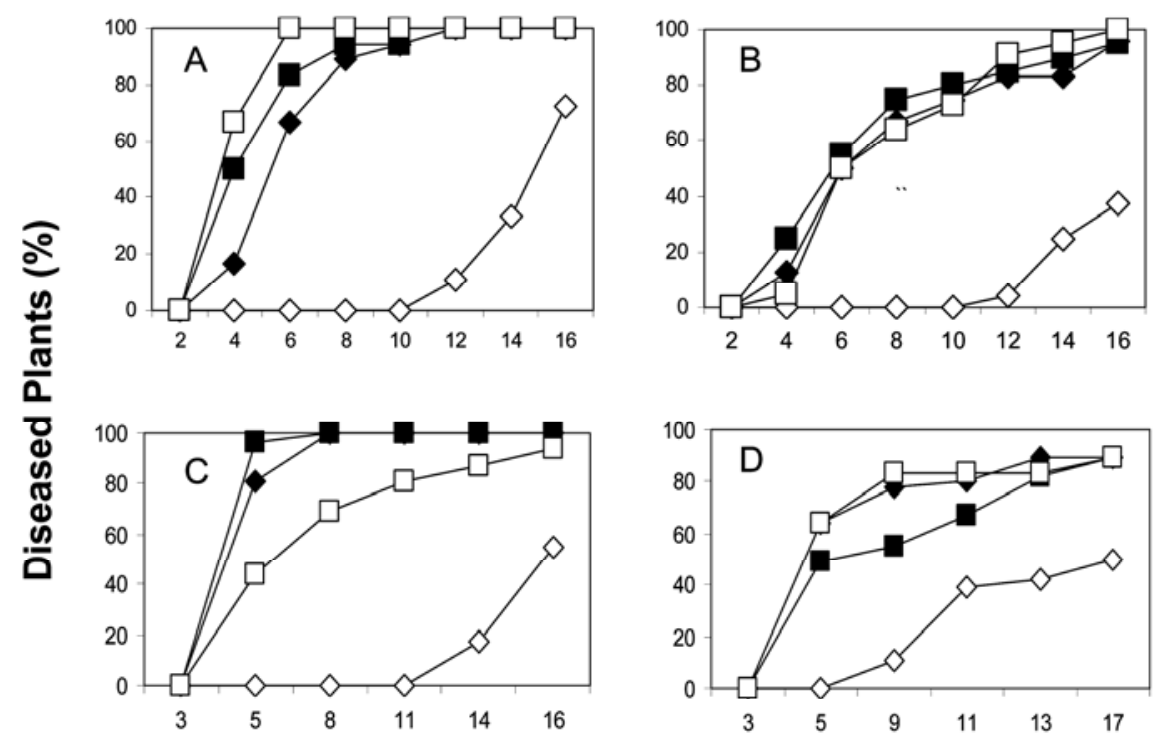

and resistant isolates treated or not treated with mefenoxam was compared, no significant difference among them was found. In addition, aggressiveness of resistant and sensitive isolates of $P$. capsici in nontreated plants in the absence of selection pressure was also similar. This contrast is a useful measure of the noncompetitive fitness in the absence of selection pressure and clearly shows that there is no loss of virulence concomitant with the gain of resistance to mefenoxam. Higher disease levels in experiment D (Fig. 4D) may be explained by inoculation of younger, more susceptible plants, and possibly by less efficient uptake of mefenoxam by their relatively smaller root systems. The fact that isolates from squash were as aggressive to the pepper host as the pepper isolates presents even more challenges for the management of this pathogen for both crops. Although there have been recent reports of insensitivity of P. capsici to mefenoxam on Cucurbitaceae elsewhere $(16,17,24)$, occurrence of a mefenoxam-resistant population of $P$. capsici on squash in North Carolina is reported here for the first time.

Our results suggest that use of mefenoxam alone should be discontinued in fields where resistant isolates are found, even if they do not account for the majority of isolates. Because of cross-tolerance of metalaxyl-mefenoxam and other acylalanines (2), all related compounds should not be used. Alternative fungicide options include phosphorous acid, ethyl phosphonates, Kocide, or chlorothalonil, dithiocarbamates, carbamates, or several new fungicides that target oomycetes for which cross-resistance to mefenoxam has not yet been reported. Interestingly, in places where phenylamide fungicides are marketed in mixtures with other chemicals such as dithiocarbamates, resistance levels among populations are much lower than in North Carolina. In a recent survey in Brazil where metalaxyl is marketed in mixed formulations with mancozeb, $94 \%$ of the isolates from pepper fields were sensitive to metalaxyl (23). On the other hand, even fields where most isolates are sensitive are not protected from the introduction of resistant isolates of $P$. capsici with irrigation water or infected transplants. The successful establishment of fungicide resistant populations in a new field is dependent on the competitive fitness of the isolates. Although our results clearly show no reduction in noncompetitive fitness associated with acquired resistance to mefenoxam, a competitive study with resistant and sensitive isolates inoculated simultaneously in planta, including population dynamics, needs to be done.

Another remaining question regards the ability of the resistant isolates to survive in soil. Survival of the pathogen in soil is an important epidemiological component of disease caused by $P$. capsici (26). Indeed, it is generally accepted that resistance to 
Table 3. Analysis of variance for rate of disease progress caused by Phytophthora capsici in pepper inoculated with mefenoxam-sensitive or -resistant isolates

\begin{tabular}{|c|c|c|c|c|c|}
\hline Nonlinear model & Source & df & $\begin{array}{c}\text { Sum of } \\
\text { squares }\end{array}$ & $\begin{array}{l}\text { Mean } \\
\text { square }\end{array}$ & $F$ test $^{\mathrm{a}}$ \\
\hline Experiment A & Regression & 3 & 200.0 & 66.6755 & \multirow{6}{*}{0.895 N.S. } \\
\hline \multirow[t]{3}{*}{ Full model $^{\mathrm{b}}$} & Residual & 69 & 14.4179 & 0.2090 & \\
\hline & Uncorrected total & 72 & 214.4 & & \\
\hline & Corrected total & 71 & 42.2901 & & \\
\hline \multirow[t]{2}{*}{ Partial model ${ }^{\mathrm{c}}$} & Regression & 2 & 199.8 & 99.9197 & \\
\hline & Residual & 70 & 14.6050 & 0.2086 & \\
\hline Experiment B & Regression & 3 & 177.5 & 59.153 & \\
\hline \multirow{3}{*}{ Full model ${ }^{\mathrm{b}}$} & Residual & 93 & 18.9022 & 0.2032 & \\
\hline & Uncorrected total & 96 & 196.4 & & \\
\hline & Corrected total & 95 & 56.5969 & & \multirow{3}{*}{1.011 N.S. } \\
\hline \multirow[t]{2}{*}{ Partial model ${ }^{\mathrm{c}}$} & Regression & 2 & 177.3 & 88.6267 & \\
\hline & Residual & 94 & 19.1077 & 0.2033 & \\
\hline Experiment $\mathrm{C}$ & Regression & 3 & 265.1 & 88.3595 & \multirow{6}{*}{0.056 N.S. } \\
\hline \multirow{3}{*}{ Full model ${ }^{\mathrm{b}}$} & Residual & 45 & 52.0326 & 1.1563 & \\
\hline & Uncorrected total & 48 & 317.1 & & \\
\hline & Corrected total & 47 & 61.9630 & & \\
\hline \multirow{2}{*}{ Partial model ${ }^{c}$} & Regression & 2 & 264.0 & \multirow{2}{*}{$\begin{array}{l}132.0 \\
1.1542\end{array}$} & \\
\hline & Residual & 46 & 53.0954 & & \\
\hline \multirow{4}{*}{$\begin{array}{l}\text { Experiment D } \\
\text { Full model }^{\mathrm{b}}\end{array}$} & Regression & 3 & 340.7 & \multirow{4}{*}{$\begin{array}{l}113.6 \\
1.0348\end{array}$} & \\
\hline & Residual & 81 & 83.8206 & & \\
\hline & Uncorrected total & 84 & 424.6 & & \\
\hline & Corrected total & 83 & 118.5 & & \multirow{3}{*}{1.905 N.S } \\
\hline \multirow[t]{2}{*}{ Partial model ${ }^{\mathrm{c}}$} & Regression & 2 & 339.9 & 169.9 & \\
\hline & Residual & 82 & 84.6911 & 1.0328 & \\
\hline
\end{tabular}

${ }^{a} F$ value tests for differences between rates of disease progress for Resistant Mef (-) and Sensitive Mef (-) isolate treatments.

${ }^{\mathrm{b}}$ A full model including all three treatments with early onset of disease progress curves.

${ }^{\mathrm{c}}$ A partial model combining the data of all treatments in pots drenched with water only (- = absence of selective pressure).

fungicides is slower to develop when the pathogen has a significant soil survival phase in its life cycle. Certainly, reports of resistance to metalaxyl-mefenoxam in $P$. capsici were delayed compared to other oomycetes that do not have a significant soil phase in their life cycle, such as $P$. infestans, Peronospora tabacina, Plasmopara viticola, Pseudoperonospora cubensis, and Bremia lactucae (19). The rate of survival of resistant and susceptible isolates of $P$ capsici in soil should also be assessed in future studies in order to characterize the parasitic and saprophytic abilities of $P$. capsici isolates resistant to mefenoxam-metalaxyl. In addition, further studies are warranted to study the impact of new formulations of fungicide mixtures (Ridomil Gold/Bravo) that are labeled on the population dynamics of fungicideresistant populations.

\section{ACKNOWLEDGMENTS}

The first author thanks CAPES-Ministry of Education, Brazil for financial support during his sabbatical leave at North Carolina State University. The authors are also grateful to Luis Alpizar Gomez and Debbie Glenn for helpful suggestions during this research.

\section{LITERATURE CITED}

1. Abdellaoui-Maane, S., Seng, J. M., Saindrenan, P., and Bompeix, G. 1988. Fosetyl-Al is effective against mutants of Phytophthora capsici resistant to metalaxyl. Cryptogam. Mycol. 9:47-56.

2. Bower, L. A., and Coffey, M. D. 1985. Development of laboratory tolerance to phosphorus acid, fosetyl-Al, and metalaxyl in Phytophthora capsici. Can. J. Plant Pathol. 7:1-6.

3. Bruin, G. C. A., and Edington, L. V. 1981.
Adaptive resistance in Peronosporales to metalaxyl. Can. J. Plant Pathol. 3:201-206.

4. Bruin, G. C. A., and Edington, L. V. 1982. Induction of fungal resistance of metalaxyl by ultraviolet irradiation. Phytopathology 72:476480.

5. Café Filho, A. C., and Ristiano, J. B. 2002. Insensitivity to mefenoxam in Phytophthora capsici isolates on pepper and squash in North Carolina. (Abstr.) Phytopathology 92:S11.

6. Cohen, Y., Reveuni, M., and Samoucha, Y. 1983. Competition between metalaxyl-resistant and sensitive strains of Pseudoperonospora cubensis on cucumber plants. Phytopathology 73:15161520.

7. Crute, I. R. 1987. The occurrence, characteristics, distribution, genetics and control of a metalaxylresistant pathotype of Bremia lactucae in the United Kingdom. Plant Dis. 71:763-767.

8. Davidse, L. C., Looyen, D., Turkensteen, L. J., and Van der Wal, D. 1981. Occurrence of metalaxyl-resistant strains of Phytophthora infestans in Dutch potato fields. Neth. J. Plant Pathol. 87:65-68.

9. Deahl, K. L., DeMuth, S. P., Linden, S. L., and Rivera-Pena, A. 1995. Identification of mating types and metalaxyl resistance in North American populations of Phytophthora infestans. Am. Potato J. 72:35-49. 1993. Testing for resistance to metalaxyl in $P h y$ tophthora infestans isolates from north-western Washington. Am. Potato J. 70:779-795.

11. Dowley, L. J., and O'Sullivan, E. 1981. Metalaxyl-resistant strains of Phytophthora infestans (Mont.) De Bary in Ireland. Potato Res. 24:417-421.

12. Ferrin, D. M., and Rohde, R. G. 1992. In vivo expression of resistance to metalaxyl by a nursery isolate of Phytophthora parasitica from $\mathrm{Ca}$ tharanthus roseus. Plant Dis. 76:82-84.

13. Hausbeck, M. K., and Lamour, K. H. 2004. Phytophthora capsici on vegetable crops: RePlant Dis. 88:1292-1303.
10. Deahl, K. L., Inglis, D. A., and DeMuth, S. P. search progress and management challenges.
14. Kadish, D., and Cohen, Y. 1988. Fitness of Phytophthora infestans isolates from metalaxylsensitive and -resistant populations. Phytopathology 78:912-915.

15. Kannwisher, M. E., and Mitchell, D. J. 1978. The influence of a fungicide on the epidemiology of black shank in tobacco. Phytopathology 68:1760-1765.

16. Lamour, K. H., and Hausbeck, M. K. 2000. Mefenoxam insensitivity and the sexual stage of Phytophthora capsici in Michigan cucurbit fields. Phytopathology 90:396-400.

17. Mathis, W. L., Williams-Woodward, J., and Csinos, A. S. 1999. Insensitivity of Phytophthora capsici to mefenoxam in Georgia. (Abstr.) Phytopathology 89:S49.

18. McDonald, M. B., Elliot, L. S., and Sweeny, P. M. 1994. DNA extraction from dry seed for RAPD analysis in varietal identification studies. Seed Sci. Technol. 22:171-176.

19. Morton, H. V., and Urech, P. A. 1988. History of the development of resistance to phelylamide fungicides. Pages 59-60 in: Fungicide Resistance in North America. C. E. Delp, ed. American Phytopathological Society, St. Paul MN.

20. North Carolina Agricultural Chemical Manual. 2008. NC Cooperative Extension Service, Raleigh, NC.

21. Parra, G., and Ristaino, J. 1998. Insensitivity to Ridomil Gold (mefenoxam) found among field isolates of Phytophthora capsici causing Phytophthora blight on bell pepper in North Carolina and New Jersey. Plant Dis. 82:711.

22. Parra, G., and Ristaino, J. B. 2001. Resistance to mefenoxam and metalaxyl among field isolates of Phytophthora capsici causing Phytophthora blight of bell pepper. Plant Dis. 85:1069-1075.

23. Paz Lima, M. L., Reis, A., Boiteux, L. S., Vargas, A. M., Jesus, S. I., Lopes, C. A., and Cafe Filho, A. C. 2004. Sensibildade de isolados brasileiros de Phytophthora capsici a metalaxyl. (Abstr.) Fitopatol. Bras. 29:103

24. Ploetz, R. C., Haynes, J., Heine, G., and Watson, M. 2001. Investigating factors that may contribute to the increased prevalence of Phytophthora capsci-induced diseases in South Florida. (Abstr.) Phytopathology 91:S72.

25. Reuveni, M., Eyal, M., and Cohen, Y. 1980. Development of resistance to metalaxyl in Pseudoperonospora cubensis. Plant Dis. 64:1108-1109.

26. Ristaino, J. B., and Johnston, S. A. 1999. Ecologically based approaches to management of Phytophthora blight on bell pepper. Plant Dis. 83:1080-1089.

27. Ristaino, J. B., Madritch, M., Trout, C. L., and Parra, G. 1998. PCR amplification of ribosomal DNA for species identification in the plant pathogen genus Phytophthora. Appl. Environ. Microbiol. 64:948-954.

28. Russell, P. E. 1995. Fungicide resistance: Occurrence and management. J. Agric. Sci. (Camb.) 124:317-323.

29. Sanders, P. L. 1984. Failure of metalaxyl to control Pythium blight on turf grass in Pennsylvania. Plant Dis. 68:776-777.

30. Taylor, R. J., Salas, B., Secor, G. A., Rivera, V., and Gudmestad, N. C. 2002. Sensitivity of North American isolates of Phytophthora erythroseptica and Pythium ultimum to mefenoxam (metalaxyl). Plant Dis. 86:797-802.

31. Timmer, L. W., Graham, J. H., and Zitko, S. E. 1998. Metalaxyl-resistant isolates of Phytophthora nicotianae: Occurrence, sensitivity, and competitive parasitic ability on citrus. Plant Dis. 82:254-261.

32. Wade, M. 1988. Strategies for preventing or delaying the onset of resistance to fungicides and for managing resistant occurrences. Pages 14-15 in: Fungicide Resistance in North America. C. E. Delp, ed. American Phytopathological Society, St. Paul, MN 